\title{
THE ROLE OF CONTEXT IN THE PROCESS OF SEMANTIC TRANSFORMATIONS OF A LEXICAL UNIT
}

\author{
Tatiana M. Shkapenko \\ Immanuel Kant Baltic Federal University, Kaliningrad, Russia \\ Svetlana S. Vaulina \\ Immanuel Kant Baltic Federal University, Kaliningrad, Russia
}

\begin{abstract}
The paper is devoted to the study of the role of context in the process of semantic derivation. The authors propose to distinguish between the term "semantic derivation" as a dynamic process of the appearance of a new word meaning and the term "polysemy" as the result of this process. Terminological distinction makes it possible to diversify research methods depending on the stage of semantic transformations. In the conditions of entirely completed polysemy, the speech context in which the polysemant is used serves as a means of identifying a specific lexico-semantic variant. At the current stage of semantic derivation, the context creates the necessary conditions for the emergence of a new meaning, and therefore the detection of innovative contexts in speech practice should be used for the purpose of linguistic monitoring of semantic transformations. The specific ways of changing the context in the process of neosemantization depend on the part of speech, which the word belongs to. Semantic derivation of adjective proceeds as a result of its attribution to the new object. The appearance of new meanings in the verbal units implies a change in the taxonomic class within the actant framework. In the case of a noun the context change is not of an obligatory nature and varies depending on the type of semantic transformations.

Key words: context, innovative context, semantic derivation, semantic transformations, polysemy, Russian language.

Citation. Shkapenko T.M., Vaulina S.S. The Role of Context in the Process of Semantic Transformations of a Lexical Unit. Vestnik Volgogradskogo gosudarstvennogo universiteta. Seriya 2. Yazykoznanie [Science Journal of Volgograd State University. Linguistics], 2021, vol. 20, no. 6, pp. 158-169. (in Russian). DOI: https://doi.org/ 10.15688/jvolsu2.2021.6.14
\end{abstract}

\section{РОЛЬ КОНТЕКСТА В ПРОЦЕССЕ СЕМАНТИЧЕСКИХ ПРЕОБРАЗОВАНИЙ ЛЕКСИЧЕСКОЙ ЕДИНИЦЫ}

\section{Татьяна Михайловна Шкапенко}

Балтийский федеральный университет им. И. Канта, г. Калининград, Россия

\section{Светлана Сергеевна Ваулина}

Балтийский федеральный университет им. И. Канта, г. Калининград, Россия

\footnotetext{
Аннотация. Статья посвящена изучению роли контекста в процессе семантической деривации. Авторы предлагают различать понятие семантической деривации как динамического процесса появления у слова нового значения и понятие полисемии как результат данного процесса. Четкое разграничение вышеуказанных терминов позволяет дифференцировать методы исследования в зависимости от стадии протекания семантических преобразований. В условиях уже сформировавшейся полисемии речевой контекст, в котором употребляется полисемант, служит средством идентификации конкретного лексико-семантического
} 
варианта. На стадии протекания процесса семантической деривации контекст создает необходимые условия для возникновения нового значения, в связи с чем обнаружение инновационных контекстов в речевой практике должно использоваться с целью лингвистического мониторинга семантических преобразований. Конкретные способы изменения контекста в процессе неосемантизации зависят от частеречной принадлежности слова. Семантическая деривация прилагательного протекает в результате атрибуции признака новому объекту. Появление новых значений у глагольной лексики предполагает изменение таксономического класса членов актантной рамки. В случае семантической деривации существительного изменение контекста не носит облигаторного характера и варьируется в зависимости от конкретного типа семантических преобразований.

Ключевые слова: контекст, инновационный контекст, семантическая деривация, семантические преобразования, полисемия, русский язык.

Цитирование. Шкапенко Т. М., Ваулина С. С. Роль контекста в процессе семантических преобразований лексической единицы // Вестник Волгоградского государственного университета. Серия 2, Языкознание. 2021. - T. 20, № 6. - C. 158-169. - DOI: https://doi.org/10.15688/jvolsu2.2021.6.14

\section{Введение}

Одной из основных проблем лексической семантики, как отечественной, так и зарубежной, долгое время являлось изучение полисемии. Внимание лингвистов было преимущественно направлено на установление моделей семантических сдвигов в значении слова (метафоризация, метонимизация, спецификация). В качестве основного материала исследования использовались толковые словари, фиксирующие факт многозначности слова в виде его отдельных лексикосемантических вариантов (далее - ЛСВ). В результате преобладания в науке структурного подхода акцент делался на внутреннем строении языка как автономной системы, в то время как роль человеческого фактора в изменении значения практически полностью игнорировалась. По мнению О.Б. Пономаревой, «в свете когнитивной лингвистики слово, будучи частью понятийной системы человека, обусловлено опытом его взаимодействия со средой и способностью к мышлению. $<\ldots$..> Появление производных значений объясняется тем, что в речи слова используются для наименования экстралингвистических объектов действительности - денотатов. Но в речи связь между именем и предметом устанавливается через сигнификат. За основу берутся свойства, выделенные у объекта, что позволяет говорящему (выделено нами. - T. Ш., С. В.) подводить сигнификат под определенное понятие, обладающее соответствующим обозначением в языке» [Пономарева, 2006, с. 214-215].
Такое осмысление лексической производности с точки зрения истинного, а не декларируемого в силу формальных требований антропоцентрического подхода начинает постепенно влиять на осознание лингвистами невозможности появления у слова нового значения без когнитивного «вмешательства» человека. В этой связи учеными все чаще говорится о необходимости дифференцировать термины «полисемия» и «семантическая деривация» (далее - СД), рассматривать дериватологию как самостоятельную область семантических исследований, предпринимаются попытки эмпирического анализа речеязыковых условий рождения нового смысла. В данной работе ставится цель систематизировать различные подходы к описанию полисемии и семантической деривации и выявить роль контекста как внешнего условия объективации новых значений, приписываемых лингвокреативным человеком уже существующему языковому знаку.

\section{Материал и методы}

Теоретико-методологическую основу работы составили исследования российских и зарубежных ученых, посвященные проблемам лексической семантики (Ю.Д. Апресян, В.Г. Гак, Д.Н. Шмелев, А.А. Зализняк, Г.И. Кустова, Е.В. Падучева, Р.И. Розина, И.М. Кобозева, J. Pustejovsky, C. Fillmore, G. Fauconnier и др.). Эмпирическая часть работы выполнена на современном языковом материале, однако изучение семантического развития слова невозможно без учета семантической рет- 
роспективы. Как указывал Ю.М. Лотман, «статическое состояние - это частная (идеально существующая только в абстракции) модель, которая является умозрительным отвлечением от динамической структуры, представляющей единственную реальность» [Лотман, 2001 , с. 30]. В связи с этим анализ активно протекающих в языке процессов проведен в синхронно-диахронической перспективе.

\section{Результаты и обсуждение}

\section{Полисемия и семантическая деривация}

Под полисемией понимается многозначность слов как единиц языковой системы. Согласно Д.Н. Шмелеву, «лексическая полисемия - способность одного слова служить для обозначения разных предметов и явлений действительности» [Шмелев, 1990, c. 382]. «Полисемия - наличие у одного и того же слова (у данной единицы выражения, характеризующейся всеми формальными признаками слова) нескольких связанных между собой значений, обычно возникающих в результате видоизменения и развития первоначального значения этого слова» [Ахманова, 1969, с. 335].

В лингвистике существует значительное количество определений семантической деривации (см., например: [Зализняк, 2001; Падучева, 2004; Шкапенко, Ваулина, 2020]). При общем понимании семантической деривации как смыслового развития на основе исходного, или «прототипического», значения, споры вызывает интерпретация термина в качестве обозначающего исключительно процесс либо процесс и результат одновременно. Толкование термина в его метонимическом двуединстве представлено в публикациях Т.Н. Пархоменко [Пархоменко, 2012] и Анны А. Зализняк, указывающей, что «данный термин является, по-видимому, наиболее удачным - в частности потому, что ценой довольно незначительного насилия он может быть применен не только к процессу, но и к результату» [Зализняк, 2001, с. 13]. Вто же время Е.В. Падучева указывает, что полисемию, или регулярную многозначность, «можно представить как следствие семантической деривации - это и будет динами- ческая модель многозначности [Падучева, 2004, с. 147]. К динамическому пониманию семантической деривации склонялся и В.Г. Гак, который считал СД частным случаем полисемии, то есть развитием смысла в диахроническом аспекте [Гак, 1977, c. 230]. В данной работе СД также предлагается рассматривать исключительно в процессуальном смысле, поскольку подобный подход позволяет разграничить явление полисемии как уже свершившийся факт многозначности от динамического процесса преобразования семантики.

\section{Контекст и различные подходы к его теоретическому описанию}

Различные лингвистические и толковые словари предлагают в целом сходные определения термина «контекст». «Контекст - 1. Лингвистическое окружение данной языковой единицы; условия, особенности употребления данного элемента в речи. 2. Законченный в смысловом отношении отрезок письменной речи, позволяющий установить значение входящего в него слова или фразы» [Ахманова, 1969, c. 206]. «Контекст - законченная в смысловом отношении часть текста, высказывания, позволяющая установить значение входящего в нее слова или фразы» (СТС, с. 286).

Как видим, определения не только содержат объяснение термина с точки зрения его внешней представленности, но и указывают на выполняемую контекстом смыслоразличительную функцию. Иначе говоря, дефиниции имплицируют присущую языковым знакам полисемичность.

В работах различной проблематики находим более широкое понимание контекста, не ограничивающееся его вербальной формой экспликации. Так, И.В. Арнольд разделяет контекст на собственно лингвистический - языковое окружение лексической единицы, необходимое и достаточное для определения ее значения, и экстралингвистический - невербальный, представленный ситуацией общения [Арнольд, 2002, с. 37]. И.Г. Торсуева предлагает разграничивать контекст эксплицитный и имплицитный, который основан на пресуппозициях, позволяющих участникам общения иденти- 
фицировать смысл речи [Торсуева, 1990, c. 238]. Существуют и другие классификации контекстов (подробно см.: [Воркачев, Воркачева, 2020]).

Многие исследователи указывают на значимость контекста в выборе одного из лексико-семантических вариантов полисеманта. Подчеркивается, что «роль контекста очень важна при явлении полисемии, так как только благодаря контексту возможно выявить определенное значение слова, возникающее в связи с его употреблением» [Галеева, Казиахмедова, Янова, 2017, с. 791]. Предлагается разделение контекстов на однотипные и разнотипные: «контексты, выступая в которых слово называет предметы разных классов, называются разнотипными. В разнотипных контекстах реализуются разные словарные значения одного и того же слова» [Арбекова, 1977, с. 81-82].

Ученые, изучающие функциональные свойства контекста, отмечают, что «как средство семантической идентификации и инструмент лингвистического анализа контекст используется лишь при исследовании и описании употребления многозначных лексических и грамматических единиц» [Воркачев, Воркачева, 2020, с. 112-113]. Основная часть работ такого рода связана, по мнению С.Г. Воркачева и Е.А. Воркачевой, с установлением типов контекста в зависимости от их «разрешающей способности» снять полисемию языковой единицы в процессе восприятия речевого высказывания [Воркачев, Воркачева, 2020, с. 112-113]. Потребность в выборе конкретного значения слова возникает как при обмене сообщениями на одном языке, так и при межъязыковой коммуникации, и в первую очередь в процессе перевода с одного языка на другой.

Однако в какой бы тематической плоскости не осуществлялся анализ контекста, практически для всех работ характерен статичный подход к изучению полисемии как уже свершившегося языкового факта, зафиксированного словарями. Иначе обстоит дело с анализом контекста в динамическом аспекте, когда речь идет не о его роли в интерпретации лексико-семантических вариантов многозначного слова, а о роли в процессе появления нового значения. Примечательно, что тот неоспоримый факт, что именно контексты ста- новятся вербальной / невербальной средой, разграничивающей значения полисемичного слова, не становится достаточно убедительным основанием для того, чтобы попытаться экстраполировать его на динамическую ситуацию порождения нового смысла. На наш взгляд, предположение об определяющей роли инновационного контекста в процессе семантической деривации представляется вполне оправданным и подлежащим лингвистической верификации.

Распространенные в лингвистике утверждения о том, что «языковое поведение слова (сочетаемость, состав грамматических форм и их значение, фразовое ударение и т. п.) определяется его значением, а значение изменчиво, подвижно» [Падучева, 2004, с. 4], создают впечатление, что значение изменяется само по себе, вслед за чем уже происходит изменение контекста. Сделать шаг от аксиомы о роли контекста как индикатора конкретного смысла многозначной лексемы к гипотезе о том, что первым шагом к появлению у слова нового значения является его творческое употребление в инновационном контексте, мешает, вероятно, инертность мышления, а возможно, как это будет показано ниже, и гетерогенность языковых способов объективации контекста.

Большинство исследований, обращенных к проблематике полисемии или семантической деривации, нацелены на выявление и систематизацию основных типов изменения значения. Как говорит Дж. Пустеевский, такие работы просто перечисляют возможные расширения смысла («simply enumerates all possible sense extensions») [Pustejovsky, 1998a, p. 2]. В противовес данному вектору исследований в области лексической семантики Дж. Пустеевский декларирует функционально-динамический подход к изучению полисемии, при котором репрезентации различных смыслов интерпретируются им как «часть композиционного процесса». Данный подход описывается лингвистом в терминах «генеративных моделей лексикона» («generative models of the lexicon») и, кроме его работ, представлен также в статьях Ч. Филлмора [Fillmore, Kay, O'Connor, 1988].

В статье «The Generative Lexicon» $(« \Gamma е-$ неративность и объяснение в семантике») 
Дж. Пустеевский подчеркивает, что предлагаемый им подход к изучению полисемии имеет динамический характер и направлен на поиски ответа на вопрос, каким образом новые смыслы могут возникать композиционно. Приводя примеры слов, меняющих свое значение в контексте, Дж. Пустеевский вводит термин «qualia structures», который можно интерпретировать как семантические «структурные качества» лексических единиц, предопределяющие генерирование ими семантических преобразований в рамках различных контекстов. По мнению исследователя, над этими квалиа-структурами действуют композиционные правила, инкорпорирующие специальные приемы для контекстуальной детерминации конкретного значения [Pustejovsky, 1998b, p. 289]. Дж. Пустеевский подчеркивает, что его теория генеративного лексикона отвечает на эмпирически сложные вопросы: каким образом слова могут иметь разные значения в разных контекстах и как новые смыслы могут возникать композиционно [Pustejovsky, 1998b, p. 289]?

О роли контекста в развитии у слова новых смыслов говорит и Ж. Фоконье. По его мнению, если для лингвистических штудий в двадцатом столетии характерным являлось интутитивное приписывание каждой форме значения независимо от контекста, то исследования значения в области прагматики показали, что допущение о существовании инвариантного значения было слишком упрощенным. Контекст имеет значение (Context matters) [Fauconnier, 2004, p. 658].

Н. Эванс и Д. Вилкинс, анализируя процесс семантического расширения на материале перцептивных глаголов, также приходят к выводу о предопределяющей роли контекста в изменении значения слова: значение $B$ часто появляется (comes into existence), поскольку регулярно возникающий (новый) контекст обеспечивает процесс контекстуального обогащения от смысла $A$ до смысла $B$. Впоследствии это контекстное значение может стать лексикализованным до такой степени, что больше не будет нуждаться в поддержке данным контекстом [Evans, Wilkins, 2000, p. 550]. Однако первичным условием для появления у слова нового значения является его употребление в инновационном лексическом окружении.

\section{Контекстуальные условия семантической деривации предикатной лексики}

Представляется очевидным, что характер лексико-синтаксической сочетаемости слова напрямую зависит от его частеречной принадлежности. Наиболее изучена с точки зрения синтагматических особенностей адъективная семантическая деривация (А.Н. Шрамм, Е.М. Вольф, М.В. Сандакова и др.). М.В. Сандакова указывает, что «свойства в мире не существуют вне предметов... ...Языковое представление свойства и его носителя посредством различных слов является результатом абстрагирующей деятельности нашего сознания» [Сандакова, 2010, c. 202]. Ученый отмечает, что процесс семантических преобразований прилагательного может в связи с этим получать единственную форму экспликации - изменять сочетаемость в результате переадресовки свойства от одного предмета к другому [Сандакова, 2010, c. 202], и выделяет регулярные модели СД прилагательного: метафоризация, метонимия и специализация отношения, под которой понимается добавление нового семантического компонента, сужающего или специализирующего значение [Сандакова, 2019, с. 123-124].

В качестве эмпирического свидетельства определяющей роли контекста в процессе СД прилагательного может служить использование так называемых правил-фильтров снятия многозначности в текстах Национального корпуса русского языка (далее - НКРЯ). Как разъясняют специалисты в области компьютерной лингвистики, «действие таких правил основано на том, что в контексте слово имеет только одно значение. Соответственно, если для каждого из значений данного слова удастся задать параметры контекста, в котором это значение реализуется, то эту информацию можно затем использовать для автоматического определения значения слова в тексте» [Рахилина, Карпова, Резникова, 2009 , с. 422-421]. В качестве теоретической базы использованного подхода исследователи указывают концепции, связывающие семантику лексемы с ее поверхностной сочетаемостью, в том числе теорию «конструкционной грамматики» Ч. Филлмора [Fillmore, Kay, 
O’Connor, 1988] и концепцию генеративного лексикона Дж. Пустеевского, в которой особое внимание российские лингвисты обращают на термин «coercion», интерпретируемый как «вынуждение» к сдвигу значения лексемы в составе комплексного выражения [Pustejovsky, 1991].

Если вопрос о синтаксической сочетаемости прилагательного решается достаточно просто на базе определяемых им существительных, то вопрос о синтаксической сочетаемости глагола более сложен, поскольку глагол имеет гораздо более распространенную цепочку логико-синтаксических валентностей. В связи с этим можно предположить, что СД глаголов выражается в изменениях существующей актантной рамки, в которую входят субъект, объект и обстоятельства совершения действия.

Р.И. Розина, анализируя категориальный сдвиг актантов на материале переносного употребления глаголов в сленге, задается вопросом об обязательной смене таксономического класса действующего субъекта. В результате анализа метафорических употреблений ряда глаголов автор приходит к выводу о том, что в случае одноместного предиката «субъект обязательно меняет свой таксономический класс» [Розина, 2002, с. 4]. Например, субъектом глагола тормозить «замедлять ход» вместо транспорта становится человек в производном сленговом значении «медленно действовать» или «медленно мыслить» [Розина, 2002, с. 4]. В случае многоместных предикатов в процессе метафоризации внутри актантной рамки возникают различные типы категориальных сдвигов. Так, может одновременно изменяться таксономический класс субъекта и объекта (люди угнали лошадей - ветер угнал туман) или только объекта (женщина взяла стакан - военные взяли селение). Могут одновременно изменяться таксономический класс субъекта и места его действия. Например, прямое значение глагола слинять подвергается метафоризации в результате замены субъекта действия на человека и смены места действия на участок конкретного пространства (краски слиняли - ученик слинял с занятий). Появление нового, разговорного значения у глагола въехать основывается на смене субъекта действия (транспорт $\rightarrow$ человек) и таксо- номического класса обстоятельства (реальное пространство $\rightarrow$ интеллектуальный объект): не въехал в тему [Розина, 2002, с. 5]. В результате ученый приходит к умозаключению, что при деривации многоместных предикатов возможны различные варианты изменения таксономических классов актантов, однако в одном из них обязательно должен произойти категориальный сдвиг.

Указанные способы изменения таксономического класса субъекта и объекта стали продуктивным способом СД глаголов в 1990-е гг., когда адаптация языка к изменившимся экстралингвистическим условиям осуществлялась преимущественно на собственной языковой почве. Вариативность способов обмана в условиях первичного накопления капитала привела к СД глаголов кинуть, обуть, наколоть, жажда быстрого обогащения - к СД глаголов срубить и скосить, а естественная для «первонакопителей» капитала брутальность нравов - к СД глагола наехать, заказать или замочить. Примечательно, что основным типом категориальных сдвигов стала замена типового неодушевленного объекта действия на объект одушевленный, что грамматически маркировало изменившийся тип социальных взаимоотношений.

Кроме изменений таксономических классов актантов, подробно описанных в работе Р.И. Розиной, СД глаголов может также происходить за счет добавления к глагольному действию отсутствующего в исходном употреблении объекта либо же, напротив, за счет его устранения. Так, глагол болеть со значением физиологического состояния при добавлении объекта за кого получает значение «будучи чьим-л. болельщиком, остро переживать успехи и неудачи предмета поклонения» (CTC, с. 51), в то же время глагол зажигать, имплицирующий обязательное наличие объекта, способного воспламениться: зажигать (зажечь) «заставить гореть» лампу, огонь, свет и т. п. (МАC, т. 1, с. 520), - в переносном значении лишается данного актанта и начинает употребляться в значении «отдыхать, веселиться»: Мы так вчера зажигали!!! Mbы зажгли! (https://www.slovonovo.ru).

Изменения такого рода можно наблюдать и на примере более современных глагольных семантических дериватов. Так, актантная рамка глагола перетереть «1. Тре- 
нием разорвать, разделить надвое. 2. Трением измельчить, истереть» (МАС, т. 3, с. 101) характеризовалась ранее обязательным наличием объекта воздействия. Его устранение привело к появлению нового значения глагола «обсудить что-то, особенно какие-то проблемы» (https://teenslang.su), активно упоребляющегося в современных речевых практиках. Еще более необычной с точки зрения логики переноса и контекстуальных изменений представляется СД глагола бомбить. Субъект из прототипического самолета-бомбардировщика или управляющего им летчика заменяется человеком, занимающимся извозом, в то же время объект бомбардировок (города, здания и т. п.) устраняется из контекста. В результате новое значение объективируется в высказываниях типа Вчера целый день бомбил. Можно предположить, что в данном случае смыслоразличительную роль выполняет референтная ситуация. Семантическая связь с исходным значением, скорее всего, основана на актуализации потенциальной семы 'уничтожительная дистрибутивность'. Процесс множественного уничтожения объектов, отраженный в прямом значении глагола бомбить, приравнивается лингвокреативным номинатором к процессу множественного отъема денег. Глагол в данном инновационном употреблении лишается привычного объекта, происходит элиминация включенного актанта при одновременной таксономической замене субъекта действия на частного водителя. Изменение прототипической ситуации становится единственным условием объективации нового значения, декодирование которого требует наличия у собеседника соответствующей пресуппозиции.

Изменения в актантной рамке могут со временем лишаться внешне выраженного характера, избавляться от контекстной поддержки. Например, СД глаголов тащиться (куда?), валяться (где?) происходит посредством устранения обстоятельственного значения и добавления к глаголам косвенного объекта, каузирующего эмоционально-оценочное состояние высокой степени удовольствия (тамусь от тебя, от фильма; валяюсь от смеха и т. п.). Данная контекстуально-смысловая поддержка со временем утрачивается, и глаголы начинают употребляться как автономные предикативные еди- ницы, особенно в форме устойчивой разговорной реплики: я тащусь, я валяюсь.

Изменение актантной рамки внутри контекста может также быть связано с изменением глагольного управления. Так, глагол тоnuть, привязанный референтно к отопительным приборам и имеющий основные словарные дефиниции «разводить и поддерживать огонь в печи», «обогревать (помещения), разводя огонь в печи или включая отопительные приборы, отапливать» (МАС, т. 4, с. 382), начинает сочетаться с существительным в винительном падеже с предлогом за, приобретая в результате значение «болеть за кого-то»: Короче, топи за Сочи! (текст рекламного баннера 2018 г. в Сочи).

Описывая глагольную СД с точки зрения изменений актантной рамки, Г.И. Кустова утверждает: «На самом деле одновременно происходят два противонаправленных семантических процесса: с одной стороны, круг актантов расширяется, и глагол “вбирает” все большее количество новых объектов - и в этом смысле исходное значение и прототипическая ситуация действительно выступают как источник некой “абстрактной схемы”, под которую “подводятся" разные объекты; но с другой стороны, происходит “приспособление” глагола к новым типам объектов, семантическое согласование с их признаками, что приводит к более или менее заметному сдвигу значения и формированию новых, производных значений» [Кустова, 2000, с. 87]. Если же изменений типа актантов не происходит, то нет причин для изменения значения глагола.

Таким образом, анализ семантических преобразований глагольной лексики приводит к выводу о том, что условием объективации нового смысла глагола является изменение его контекстуального окружения. Это изменение происходит в условиях творческого, инновационного употребления слова индивидом, а уже впоследствии переходит из окказионального в узуальное.

\section{Контекстуальные условия семантической деривации предметной лексики}

Несмотря на то что в основе СД всех частей речей лежат схожие модели (метафо- 
ризация, метонимизация и спецификация), когнитивные операции в основе сдвигов значений предикатной и предметной лексики значительным образом отличаются друг от друга. Невозможность автономного существования признаков вне определяемых объектов приводит к тому, что изменение их значения представляет собой операцию по наделению признаком или действием объекта / субъекта, не входящего в группу прототипических определяемых. Номинатор в данном случае обязательно употребляет характеристику в инновационном контексте: дремлет человекдремлет лес, глубокое озеро - глубокая мысль и т. п. Контекстуальная объективация семантического сдвига является обязательным условием для возникновения нового значения предикатных слов.

Иначе обстоит дело с СД имен существительных. Они выполняют функцию номинации объектов, следовательно, в основе их СД лежит перенос имени с одного называемого объекта на другой, или смена референта. Номинативная метафора имеет целью наименование нового объекта старым именем на основе уловленного номинатором сходства, например: лента - о конвейере или о фильме, взгляд - о мнении и т. п. Номинативные акты данного типа направлены на конкретный денотат, еще не имеющий имени, и, как правило, не нуждаются в контекстуальной поддержке. Как справедливо замечает О.Б. Пономарева, «для существительных в развитии полисемии основным оказывается логический фактор, для глаголов в большинстве случаев логическая связь между исходным и производным значением перекрывается синтактико-фразеологическим окружением слова» [Пономарева, 2006, с. 214].

Действие номинативной метафоры может осуществляться как независимо от контекста (например, шар - геометрическая фигура, предмет такой формы, воздушный шар и т. п.), так и в обязательной связи с ним. В последнем случае метафорическая номинация имеет форму составного наименования Nnom. + Ngen.: спутник Земли, нос корабля, подошва горы, кольцо колбасы, луковки иерквей.

Формула атрибутивного сочетания активным образом используется также в дру- гих типах СД существительных. Исследуя изменения значений русских существительных в языке коммерции и рекламы, Е.М. Кацман приходит к выводу о том, что «процессы расширения / сужения значения слова неразрывно связаны с изменением его сочетаемости» [Кацман, 2017, с. 46]. Так, появление инновационной сочетаемости у существительного пакет (пакет акиий, предложений, услуг, инициатив, требований и т. п.) создает условия для деактуализации семы прототипического материального объекта («бумажный мешок для упаковки продуктов») и порождает новое, метафорическое значение «совокупность, комплекс». Если метафоризация существительного пакет находит выражение в конкретизирующем контексте, включающем генитивную конструкцию: пакет + сущ. Род. п. мн. ч., то в процессе СД слова продукт решающую роль в становлении нового значения играет инновационное сочетание слова с согласованным определением-прилагательным: банковский, страховой, финансовыци, инвестиционный, рекламный продукт и т. п. Е.М. Кацман отмечает, что в данных отраслях продукт не имеет материального денотата, что сближает такие употребления с абстрактным ЛСВ («результат») [Кацман, 2017, c. 47].

Анализ СД существительного рынок приводит Е.М. Кацман к выводу о том, что происходит не только расширение значения слова, но и реиерархизация сем в его семантической структуре. На первое место выходит значение, отражающее экономическое понятие, - «сфера свободного товарно-денежного обращения», в то время как бывшее ранее главным значение «место торговли» фиксируется словарями уже как второе. Среди контекстов, объективирующих новый ЛСВ, исследователь указывает сочетания свободный рынок, переход к рынку, туристический рынок, рынок жилья. На наш взгляд, данного контекстуального материала, однако, явно недостаточно для того, чтобы вывести на новый уровень значимость понятия рынка, которое составило экономическую основу трансформации России. Даже беглый анализ примеров НКРЯ позволяет выделить калькируемые с английского языка сочетания, которые выступают в роли проводников новых смыслов. Рынок подвергается антропо- 
морфизации (невидимая рука рынка, рынок быстрее успокоится, рынок оказался нечувствительным к ситуации и др.), внушается мысль о рынке как об универсальном регуляторе всех экономических процессов (саморегулируемый рынок, рынок все отрегулиру$\mathrm{em})$, как об универсальной форме конкуренции во всех областях (рынок сбыта, рынок образовательных услуг, потребительский рынок, рынок труда, рынок жсилья и т. п.). Как видим, в случае реконцептуализации понятия задействованными становятся самые разные синтактико-семантические формы инновационных контекстов. В связи с этим чрезвычайно важным представляется понимание того, что «именно скрупулезный анализ контекста употребления слова позволяет выявить семы, актуализирующиеся в его значении, и проследить возможсное направление формирования нового значения (выделено нами. - Т. Ш., C. B.» [Кацман, 2017, с. 47].

Динамический подход к выявлению лингвокогнитивных условий реализации СД существительного отличает работу В.А. Белова «Семантическая деривация имен существительных». В исследовании, основанном на данных НКРЯ и результатах эксперимента толкования носителями современного русского языка новых ЛСВ слов, акцент делается не на «моделях или типах семантических изменений (которые достаточно полно описаны в лингвистике), а на самом процессе изменения» [Белов, 2020, с. 5]. Согласно сформулированной автором гипотезе, СД имени существительного «обусловлена изменением обозначаемой словом прототипической ситуации под влиянием контекстуальной ситуаиии, представленной в высказывании» [Белов, 2020, c. 5]. Анализируя процессы изменений значения слов (стоянка, рассылка, силовики и др.) на основе их обновленных контекстуальных употреблений, В.А. Белов подчеркивает особую роль, которую играют «конкретизаторы ситуации», указывающие на использование существительного в новом значении. Контексты, в которых существительные употребляются в новом значении, ученый, вслед за Н. Энфилдом, называет «связывающими» (bridging contexts), поскольку они маскируют переход от прагматической импликации к подлинной полисемии [Enfield, 2003, p. 28-29].
Заметим, что данный термин представляется вполне адекватным с точки зрения роли контекста в закреплении нового ЛСВ, однако с точки зрения условий порождения нового смысла более релевантным, на наш взгляд, является использование термина «инновационный контекст». Именно в результате употребления «старого» языкового знака в нетипичном для него, новом контекстуальном окружении происходит возникновение его нового содержания. Новая ситуация, эксплицированная в индивидуальном лингвокреативном высказывании, постепенно получает распространение в узусе, освобождается от рамок связывающего контекста и закрепляется в значении самого слова.

\section{Заключение}

Развитие у слова нового значения происходит в результате взаимодействия двух факторов: когнитивного (логического сдвига в значении) и речеязыкового (употребления слова говорящим в инновационном контексте). Роль и соотношение этих факторов неодинаковы для различных частей речи. Процесс СД прилагательного происходит в результате приписывания свойства или признака новому объекту, что объективируется в инновационной синтагматике прилагательного. У глагола в область отраженных им лингвокогнитивных связей включаются субъект, объект и обстоятельства действия, следовательно, в процессе СД происходит обязательное изменение таксономического класса членов актантной рамки, влекущее за собой изменение контекста. Соотношение логического и речеязыкового факторов в СД имени существительного зависит от типа семантического сдвига. Если речь идет о смене именуемого денотата, то логический фактор не всегда требует использования слова в инновационном контексте. Если происходит спецификация значения (расширение или сужение смысла, реконцептуализация), использование инновационного контекста употребления слова является необходимым условием его неосемантизации. При этом способность существительного сочетаться с другими существительными, глаголами и прилагательными обусловливает значительно более широкий спектр контекстуаль- 
ных изменений. Их более подробное типологическое описание составляет перспективу изучения роли и моделей инновационного контекста в процессе семантической деривации.

\section{СПИСОК ЛИТЕРАТУРЫ}

Арбекова Т. И., 1977. Лексикология английского языка. М. : Высш. шк. 240 с.

Арнольд И. В., 2002. Стилистика. Современный английский язык. М. : Флинта : Наука. 384 с.

Ахманова О.С., 1969. Словарь лингвистических терминов. М. : Сов. энцикл. 608 с.

Белов В. А., 2020. Семантическая деривация имен существительных // Вестник Томского государственного университета. № 459. С. 5-14. DOI: $10.17223 / 15617793 / 459 / 1$.

Воркачев С. Г., Воркачева Е. А., 2020. Полисемия, контекст и трансляция смыслов // Современные исследования социальных проблем. Т. 12, №5. C. 112-125. DOI: 10.12731/2077-1770-20205-112-125.

Гак В. Г., 1977. К типологии лингвистической номинации // Языковая номинация : Общие вопросы. М. : Наука. С. 230-293.

Галеева Т. И., Казиахмедова С. Х., Янова Е. А., 2017. Явление полисемии как феномен лингвистики // Вестник Удмуртского государственного университета. Серия: История и филология. Т. 27, вып. 5. С. 784-794.

Зализняк Анна А., 2001. Семантическая деривация в синхронии и диахронии: проект «Каталога семантических переходов» // Вопросы языкознания. № 2. С. 13-25.

Кацман Е. М., 2017. О семантических трансформациях русских существительных в языке коммерции и рекламы // Научный диалог. № 2. C. 44-56. DOI: https://doi.org/10.24224/22271295-2017-2-44-56.

Кустова Г. И., 2000. Когнитивные модели в семантической деривации и система производных значений // Вопросы языкознания. № 4. C. $85-109$.

Лотман Ю. М., 2001. Семиосфера. Культура и взрыв. Внугри мыслящих миров. Статьи. Исследования. Заметки. СПб. : Искусство-СПБ. 703 с.

Падучева Е. В., 2004. Динамические модели в семантике лексики. М. : Яз. слав. культуры. 610 с.

Пархоменко Т. Н., 2012. К вопросу о семантической деривации // Вестник Кемеровского государственного университета. Т. 4, № 4 (52). C. 87-90.

Пономарева О. Б., 2006. Семантическая деривация и многозначность: неоднозначность и слияние смыслов в поэтическом тексте // Вестник
Тюменского государственного университета. №4. C. 212-217.

Рахилина Е. В., Карпова О. С., Резникова Т. И., 2009. Модели семантической деривации многозначных качественных прилагательных: метафора, метонимия и их взаимодействие // Компьютерная лингвистика и интеллектуальные технологии : материалы ежегод. Междунар. конф. «Диалог». М. : Изд-во РГГУ. С. 420-426.

Розина Р. И., 2002. Категориальный сдвиг актантов в семантической деривации // Вопросы языкознания. № 2. С. 3-15.

Сандакова М. В., 2010. Прилагательное в атрибутивном словосочетании // Ярославский педагогический вестник. Т. 1, № 4. С. 202-207.

Сандакова М. В., 2019. Способы семантической деривации и типы соотношений между значениями в семантической структуре прилагательного // Научный диалог. № 3. C. 117-131. DOI: https:// doi.org/10.24224/2227-1295-2019-3-117-131.

Торсуева И. Г., 1990. Контекст // Лингвистический энциклопедический словарь / гл. ред. В. Н. Ярцева. М. : Сов. энцикл. С. 238-239.

Шкапенко Т. М., Ваулина С. С., 2020. Проблемы терминологизации и теоретического описания уровней языковой деривации // Вестник Волгоградского государственного университета. Серия 2, Языкознание. Т. 19, № 6. C. 204-215. DOI: https://doi.org/10.15688/ jvolsu2.2020.6.16.

Шмелев Д. Н., 1990. Полисемия // Лингвистический энциклопедический словарь / гл. ред. В.Н.Ярцева. М. : Сов. энцикл. С. 382.

Enfield N., 2003. Linguistic Epidemiology: Semantics and Grammar of Language Contact in Mainland Southeast Asia. L. : Routledge Curzon. 397 p.

Evans N., Wilkins D., 2000. In the Mind's Ear: The Semantic Extensions of Perception Verbs in Australian Languages // Language. № 76. P. 546592. DOI: $10.2307 / 417135$.

Fauconnier G., 2004. Pragmatics and Cognitive Linguistics // The Handbook of Pragmatics / ed. by L. Horn, G. Ward. Oxford : Oxford University Press. P. 657-374.

Fillmore C., Kay P., O’Connor M. K., 1988. Regularity and Idiomaticity in Grammatical Constructions: The Case of Let Alone // Language. Iss. 64. P. 501-538.

Pustejovsky J., 1991. The Generative Lexicon // Computational Linguistics. № 17 (4). P. 409-441.

Pustejovsky J., 1998a. The Semantics of Lexical Underspecification // Folia Linguistica. Vol. 32, № 3/4. P. 1-28.

Pustejovsky J., 1998b. Generativity and Explanation in Semantics: A Reply to Fodor and Lepore // Linguistic Inquiry. Vol. 29, № 2. P. 289-311. 


\section{СЛОВАРИ}

$M A C$ - Словарь русского языка : в 4 т. / под ред. А. П. Евгеньевой. М. : Рус. яз., 1981-1984. T. 1. 1981.698 c. ; Т. 2. 1983.736 c. ; Т. 3. 1983. 752 c.; Т. 4. 1984.794 c.

CTC - Современный толковый словарь русского языка / под ред. С. А. Кузнецова. СПб. : Норинт, $2003.960 \mathrm{c}$.

\section{REFERENCES}

Arbekova T.I., 1977. Leksikologiya angliyskogo yazyka [Lexicology of the English Language]. Moscow, Vysshaya shkola Publ. 240 p.

Arnold I.V., 2002. Stilistika. Sovremennyy angliyskiy yazyk [Stylistics. Modern English]. Moscow, Flinta Publ., Nauka Publ. 384 p.

Akhmanova O.S., 1969. Slovar lingvisticheskikh terminov [Dictionary of Linguistic Terms]. Moscow, Sovetskaya entsiklopediya Publ. 608 p.

Belov V.A., 2020. Semanticheskaya derivatsiya imen sushchestvitelnykh [Semantic Derivation of Nouns]. Vestnik Tomskogo gosudarstvennogo universiteta [Tomsk State University Journal], no. 459, pp. 5-14. DOI: 10.17223/15617793/459/1.

Vorkachev S.G., Vorkacheva E.A., 2020. Polisemiya, kontekst i translyatsiya smyslov [Polysemy, Context and Meanings Transference]. Sovremennye issledovaniya sotsialnykh problem [Modern Studies of Social Issues], vol. 12 , no. 5, pp. 112-125. DOI: 10.12731/20771770-2020-5-112-125.

Gak V.G., 1977. K tipologii lingvisticheskoy nominatsii [On the Typology of Linguistic Nomination]. Yazykovaya nominatsiya: Obshchie voprosy [Language Nomination: General Questions]. Moscow, Nauka Publ., pp. 230-293.

Galeeva T.I., Kaziahmedova S.H., Janova E.A., 2017. Yavlenie polisemii kak fenomen lingvistiki [Polysemy As a Linguistics Phenomenon]. Vestnik Udmurtskogo gosudarstvennogo universiteta. Seriya Istoriya i filologiya [Bulletin of Udmurt University. Series History and Philology], vol. 27, iss. 5, pp. 784-794.

Zaliznjak Anna A., 2001. Semanticheskaya derivatsiya v sinkhronii i diakhronii: proekt «Kataloga semanticheskikh perekhodov» [Semantic Derivation in Synchrony and Diachrony: The Project of the "Catalog of Semantic Transitions"]. Voprosy yazykoznaniya [Topics in the Study of Language], no. 2, pp. 13-25.

Katsman E.M., 2017. O semanticheskikh transformatsiyakh russkikh sushchestvitelnykh v yazyke kommertsii i reklamy [On Semantic
Transformations of Russian Nouns in the Language of Commerce and Advertising]. Nauchnyi dialog, no. 2, pp. 44-56. DOI: https:// doi. org/10.24224/2227-1295-2017-2-44-56.

Kustova G.I., 2000. Kognitivnye modeli v semanticheskoy derivatsii i sistema proizvodnykh znacheniy [Cognitive Models in Semantic Derivation and the System of Derived Values]. Voprosy yazykoznaniya [Topics in the Study of Language], no. 4, pp. 85-109.

Lotman Yu.M., 2001. Semiosfera. Kultura i vzryv. Vnutri myslyashchikh mirov. Stat'i. Issledovaniya. Zametki [Semiosphere. Culture and Explosion. Inside the Thinking Worlds. Articles. Researches. Notes]. Saint Petersburg, Iskusstvo-SPB Publ. 703 p.

Paducheva E.V., 2004. Dinamicheskie modeli v semantike leksiki [Dynamic Models in the Semantics of Vocabulary]. Moscow, Yazyki slavyanskoy kultury Publ. 610 p.

Parkhomenko T.N., 2012. K voprosu o semanticheskoy derivatsii [On Semantic Derivation]. Vestnik Kemerovskogo gosudarstvennogo universiteta [Bulletin of Kemerovo State University], vol. 4, no. 4 (52), pp. 87-90.

Ponomareva O.B., 2006, Semanticheskaya derivatsiya i mnogoznachnost: neodnoznachnost i sliyanie smyslov v poeticheskom tekste [Semantic Derivation and Polysemy: Ambiguity and Merging of Meanings in a Poetic Text]. Vestnik Tyumenskogo gosudarstvennogo universiteta [Tyumen State UniversityHerald], no. 4, pp. 212-217.

Rakhilina E.V., Karpova O.S., Reznikova T.I., 2009. Modeli semanticheskoy derivatsii mnogoznachnykh kachestvennykh prilagatelnykh: metafora, metonimiya i ikh vzaimodeystvie [Models of Semantic Derivation of Polysemic Qualitative Adjectives: Metaphor, Metonymy and Their Interaction]. Kompyuternaya lingvistika $i$ intellektualnye tekhnologii: materialy ezhegod. Mezhdunar. konf. «Dialog» [Computational Linguistics and Intellectual Technologies. Proceedings of the Annual International Conference “Dialog"]. Moscow, Izd-vo RGGU, pp. 420-426.

Rozina R.I., 2002. Kategorialnyy sdvig aktantov v semanticheskoy derivatsii [Categorical Shift of Actants in Semantic Derivation]. Voprosy yazykoznaniya [Topics in the Study of Language], no. 2, pp. 3-15.

Sandakova M.V., 2010. Prilagatelnoe v atributivnom sochetanii [Adjective in an Attributive Word Combination]. Yaroslavskiy pedagogicheskiy vestnik [Yaroslavl Pedagogical Bulletin], vol. 1, no. 4, pp. 202-207.

Sandakova M.V., 2019. Sposoby semanticheskoy derivatsii i tipy sootnosheniy mezhdu 
znacheniyami v semanticheskoy strukture prilagatelnogo [Ways of Semantic Derivation and Types of Relations Between Meanings in Adjective Semantic Structure]. Nauchnyi dialog, no. 3, pp. 117-131. DOI: https://doi.org/ 10.24224/2227-1295-2019-3-117-131.

Torsueva I.G., 1990. Kontekst [Context]. Yartseva V.N., ed. Lingvisticheskiy entsiklopedicheskiy slovar [Linguistic Encyclopedic Dictionary]. Moscow, Sovetskaya entsiklopediya Publ., pp. 238-239.

Shkapenko T.M., Vaulina S.S., 2020. Problemy terminologizatsii i teoreticheskogo opisaniya urovney yazykovoy derivatsii [Problems on Terminology and Theoretical Description of Language Derivation Levels]. Vestnik Volgogradskogo gosudarstvennogo universiteta. Seriya 2. Yazykoznanie [Science Journal of Volgograd State University. Linguistics], vol. 19, no, 6, pp. 204-215. DOI: https://doi.org/10.15688/ jvolsu2.2020.6.16.

Shmelev D.N., 1990. Polisemija [Polysemy]. Yartseva V.N., ed. Lingvisticheskiy entsiklopedicheskiy slovar [Linguistic Encyclopedic Dictionary]. Moscow, Sovetskaya entsiklopediya Publ., p. 382.

Enfield N., 2003. Linguistic Epidemiology: Semantics and Grammar of Language Contact in Mainland Southeast Asia. London, Routledge Curzon. 397 p.

Evans N., Wilkins D., 2000. In the Mind's Ear: The Semantic Extensions of Perception Verbs in
Australian Languages. Language, no. 76, pp. 546-592. DOI: 10.2307/417135.

Fauconnier G., 2004. Pragmatics and Cognitive Linguistics. Horn L., Ward G., eds. The Handbook of Pragmatics. Oxford, Oxford University Press, pp. 657-374.

Fillmore C., Kay P., O’Connor M.K., 1988. Regularity and Idiomaticity in Grammatical Constructions: The Case of Let Alone. Language, iss. 64, pp. 501-538.

Pustejovsky J., 1991. The Generative Lexicon. Computational Linguistics, no. 17 (4), pp. 409-441.

Pustejovsky J., 1998a. The Semantics of Lexical Underspecification. Folia Linguistica, vol. 32, no. 3/4, pp. 1-28.

Pustejovsky J., 1998b. Generativity and Explanation in Semantics: A Reply to Fodor and Lepore. Linguistic Inquiry, vol. 29, no. 2, pp. 289-311.

\section{DICTIONARIES}

Evgenyeva A.P., ed. Slovar russkogo yazyka: v 4 t. [Dictionary of the Russian Language. In 4 Vols.] Moscow, Russkiy yazyk Publ., 1981-1984. Vol. 1, 1981. 698 p.; vol. 2, 1983. 736 p.; vol. 3, 1983. 752 p.; vol. 4, 1984. 794 p.

Kuznetsov S.A., ed. Sovremennyy tolkovyy slovar russkogo yazyka [Modern Explanatory Dictionary of the Russian Language]. Saint Petersburg, Norint Publ., 2003. 960 p.

\section{Information About the Authors}

Tatiana M. Shkapenko, Doctor of Sciences (Philology), Professor, Institute of Humanities, Immanuel Kant Baltic Federal University, Aleksandra Nevskogo St, 14, 236041 Kaliningrad, Russia, tshkapenko@kantiana.ru, https://orcid.org/0000-0002-6892-4205

Svetlana S. Vaulina, Doctor of Sciences (Philology), Professor, Institute of Humanities, Immanuel Kant Baltic Federal University, Aleksandra Nevskogo St, 14, 236041 Kaliningrad, Russia, svaulina@mail.ru, https://orcid.org/0000-0001-7109-2836

\section{Информация об авторах}

Татьяна Михайловна Шкапенко, доктор филологических наук, профессор Института гуманитарных наук, Балтийский федеральный университет им. И. Канта, ул. Александра Невского, 14, 236041 г. Калининград, Россия, tshkapenko@kantiana.ru, https://orcid.org/0000-0002-6892-4205

Светлана Сергеевна Ваулина, доктор филологических наук, профессор Института гуманитарных наук, Балтийский федеральный университет им. И. Канта, ул. Александра Невского, 14, 236041 г. Калининград, Россия, svaulina@mail.ru, https://orcid.org/0000-0001-7109-2836 